\title{
Inhibition of Cracks on the Surface of Cement Mortar Using Estabragh Fibers
}

\author{
Tahereh Soleimani, ${ }^{1}$ Ali Akbar Merati, ${ }^{2}$ Masoud Latifi, ${ }^{1}$ and Ali Akbar Ramezanianpor ${ }^{3}$ \\ ${ }^{1}$ Textile Engineering Department, Amirkabir University of Technology, Tehran, Iran \\ ${ }^{2}$ Advanced Textile Materials and Technology (ATMT) Research Institute, Amirkabir University of Technology, Tehran, Iran \\ ${ }^{3}$ Concrete Technology and Durability Research Center, Amirkabir University of Technology, Tehran, Iran \\ Correspondence should be addressed to Ali Akbar Merati; merati@aut.ac.ir
}

Received 14 May 2013; Revised 18 July 2013; Accepted 27 July 2013

Academic Editor: Rui Huang

Copyright (C) 2013 Tahereh Soleimani et al. This is an open access article distributed under the Creative Commons Attribution License, which permits unrestricted use, distribution, and reproduction in any medium, provided the original work is properly cited.

\begin{abstract}
The influence of adding Estabragh fibers into the cement composites of mortar on surface cracks and mechanical properties of mortar has been studied at various fiber proportions of $0.25 \%, 0.5 \%$, and $0.75 \%$. The mortar shrinkage was evaluated by counting the number of cracks and measuring the width of cracks on the surface of mortar specimens. Although the Estabragh fibers loss their strength in an alkali environment of cement composites, the ability of Estabragh fibers to bridge on the microcracks in the mortar matrix causes a decrease in the number of cracks and in their width on the surface of the mortar samples in comparison with the plain mortar. However, considering the mechanical properties of specimens such as bending strength and compressive strength, among all fiber proportions, only the specimens with $0.25 \%$ of Estabragh fiber performed better in all respects compared to the physical and mechanical properties of reinforced cement composite of mortar. Consequently, by adding $0.25 \%$ of Estabragh fibers to the cement mortar, a remarkable inhibition in crack generation on fiber-containing cement composite of mortar is achieved.
\end{abstract}

\section{Introduction}

Estabragh fibers are cellulosic seed fibers growing on single cells in a large seed of the plant. These fibers are naturally hollow, with a thin wall relative to their diameter, and are therefore lightweight. They are planted in some regions of Africa and Middle East. These fibers are straight without crimp along their length. In the previous research works, some mechanical properties and structural parameters of these fibers have been studied [1]. These fibers have low extension of about $2.2 \%$ and higher modulus in comparison with other general textile fibers [1].

Cement mortar and concrete made with Portland cement is a kind of the most commonly used construction materials in the world. These materials have inherently brittle nature and have some dramatic disadvantages such as poor deformability and weak crack resistance in the practical usage [24]. To improve the brittle nature of cement composites, the application of discrete fibers has been proposed by many researchers [5-7]. Reinforcement of cement composite with fibers has been proved an effective and economical way to convert cementitious material into a tough and ductile product $[2,8-11]$. At first, asbestos fibers were used in the Hatschek process to produce fiber-reinforced cement sheets. Researchers showed excellent performance in building material in various forms and styles during the last century. But the usage of this fiber may be accompanied with dangers for human health [2]. Thereafter, by introducing the various types of synthetic fibers, many efforts have been made to replace the asbestos fibers. The most frequently used reinforcement fibers in the last decades were included organic fibers (acrylic, polyvinyl alcohol, polyolefin, polyethylene, and polypropylene) and inorganic fibers (alkali-resistant glass and carbon) [10].

The need for materials having specific characteristics for specific purposes, while at the same time being nontoxic and environmentally friendly, is increasing, due to a lack of resources and increasing environmental pollution. Thus, research on the development of composites prepared using new fibrous materials is being actively pursued. 
Brittle matrices, such as unreinforced mortar and concrete, lose their tensile load-carrying capacity almost immediately after formation of the first crack in their matrices. The addition of fibers into cement composites can increase the toughness of cementitious matrices significantly. Performance improvement of fiber reinforced concrete can be attributed to the point where fibers resist cracking generation $[6,12]$. The efficacy of fiber-reinforcement in the grab of cracking, which results from drying shrinkage, has been proved $[13,14]$. Also, it has been proved [6] that physical and mechanical properties of reinforced concrete improve with increasing the volume fraction of the fibers in cement matrix. It was reported that application of nylon and polypropylene fibers improves the plain concrete properties including splitting tensile strength, first crack strength, and impact resistance [15]. Alhozaimy et al. [16] observed that an additional amount of $0.1 \%$ polypropylene fibers in the plain concrete had $44 \%$ increase in flexural toughness of the concrete. Some researchers also reported evidence of small but favorable effects of adding fiber to cementitious material on toughness [17-21]. Mindess and Vondran (1988) reported that compressive strength increased by about $25 \%$ at $0.5 \%$ volume fraction of polypropylene fibers in the concrete mixture design [22]. Hughes and Fattuhi [23] suggested that with increasing fiber content, the compressive strength of concrete decreases while the flexural properties of concrete are improved.

However, there is no study about the adding of Estabragh fibers into the cement composites and the best volume fractions of fibers in them. The higher modulus and lower extension of these fibers in comparison with other organic fibers make them useful to be used in the cement composites. This study presents comprehensive experimental data regarding the effects of adding Estabragh fibers with different fiber volume fractions on the physical and mechanical properties of cement mortar.

\section{Materials and Methods}

Estabragh fibers are fibers of seed vegetables that are planted in desert areas of Africa and Middle East. The fibers grow in groups inside the seed, and each staple contains uniform, longitudinally oriented fibers. The fibers are straight, and there is no crimping along the fiber length (Figure 1(a)). As this figure shows, the fibers have a smooth surface and are mostly cylindrical. The fibers are hollow in nature, and the ratio of the hollow area to the fibrous area is considerable (Figure 1(a)). The hollowness of the fibers governs the mechanical behavior in tension and bending. The physical properties of the fibers are presented in Table 1.

Because of hydration process and the generation of $\mathrm{Ca}(\mathrm{OH})_{2}$, Portland cement has a strong alkali environment $[24,25]$. The alkali environment of cement system may cause the degradation of fibers and loss of their tensile strength. Consequently, it is important to investigate the alkali resistance of used fibers in cementitious materials. To evaluate the fiber resistance, they are soaked in $\mathrm{NaOH}$ $(=40 \mathrm{~g} / \mathrm{L})$ with $\mathrm{pH}=12$ to examine their strength in the alkali environments. Therefore, the tensile strength of them
TABLE 1: Estabragh fibers properties.

\begin{tabular}{lc}
\hline Fiber mean length $(\mathrm{mm})$ & 26.6 \\
Fiber tip diameter $(\mu \mathrm{m})$ & 15.76 \\
Fiber middle diameter $(\mu \mathrm{m})$ & 28.93 \\
Fiber end diameter $(\mu \mathrm{m})$ & 39.16 \\
Fiber mean strength at breaking $(\mathrm{CN})$ & 3.65 \\
$\begin{array}{l}\text { Mean strength at breaking after 28 days in } \\
\text { caustic soda }(\mathrm{CN})\end{array}$ & 2.17 \\
\hline
\end{tabular}

TABLE 2: Mortar mixture proportions $\left(\mathrm{kg} / \mathrm{m}^{3}\right)$.

\begin{tabular}{lccc}
\hline $\begin{array}{l}\text { Cement } \\
\left(\mathrm{kg} / \mathrm{m}^{3}\right)\end{array}$ & $\begin{array}{c}\text { Sand } \\
\left(\mathrm{kg} / \mathrm{m}^{3}\right)\end{array}$ & $\begin{array}{c}\text { Water } \\
\left(\mathrm{kg} / \mathrm{m}^{3}\right)\end{array}$ & Estabragh fibers $(\%)$ \\
\hline 625 & 1719 & 325 & $0,0.25,0.5$, and 0.75 \\
\hline
\end{tabular}

was tested after 28 days of exposure to alkali condition. Single fiber tensile test was performed under standard environment on a Fafegraph HR (Monchengladbach, Germany) tensile tester machine with a constant rate of crosshead speed of $20 \mathrm{~mm} / \mathrm{min}$ in accordance with the requirements of ISO 527.

The cement used in this study was ordinary Portland cement, which corresponds to ASTM Type II. In this study, the following types of mixtures were prepared (Table 2). All mixtures were mixed in a conventional rotary drum concrete mixer with a capacity of $0.04 \mathrm{~m}^{3}$.

Estabragh fibers-reinforced mortar specimens were prepared at three different fractions of $0.25 \%, 0.5 \%$, and $0.75 \%$ of Estabragh fibers. The fractions of the Estabragh fibers are calculated by weight of the cement in the composite. Plain mortar was also prepared as control specimen. Total dosage of Estabragh fibers in mixture was maintained up to $0.75 \%$, primarily from the point of view of providing good workability and without balling the fibers during mixing. At fibers volume fraction of higher than $0.75 \%$, fibers started to make balls in the mixture.

The cement was added to the water in a rotating mixer and dissolved for about 30 seconds. Then, the sand was added to the mixture and mixed for about 30 seconds. Fibers were wetted by water then were dispersed by hand in the mixture to achieve a uniform distribution throughout the mortar, which was mixed for a total of $4 \mathrm{~min}$. There were no fibers balling during mixing and placing for all the mortar after mixture. Fresh mortar was cast in two stages in the wooden moulds and compacted on a vibrating table. For the curing function, the specimens were kept covered in their molds for $24 \mathrm{~h}$ in an oven of $38^{\circ} \mathrm{C}$. There was less bleeding in the fiber mortar compared to that of the control mortar. Most of the cracks are generated on the surface of the mortar before the first 6 hours and then appeared before the first 24 hours. Therefore, the number of cracks on the surface of 24-hour-old demoulded specimen is counted and the width of all cracks is measured using a microscope, and then the mean of crack width is calculated.

To measure the mechanical properties of the cement composite of mortar, the fresh mortar mixture was prepared then casted in the steel moulds of $16 \times 4 \times 4 \mathrm{~cm}$ dimensions 


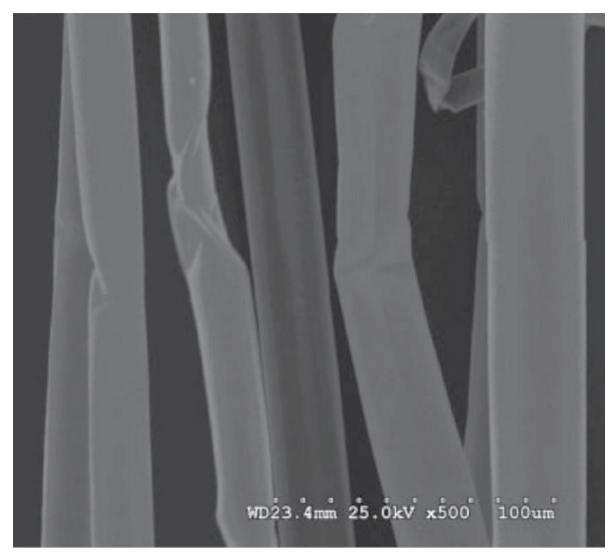

(a)

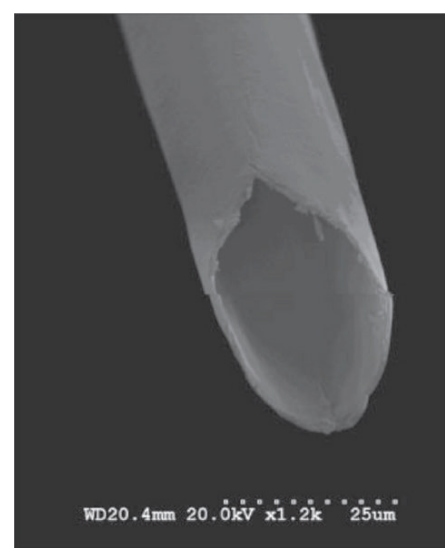

(b)

FIGURE 1: (a) SEM image showing the longitudinal features of the Estabragh fibers. (b) SEM image depicting the unique hollow center and thin cell wall of the Estabragh fiber [26].

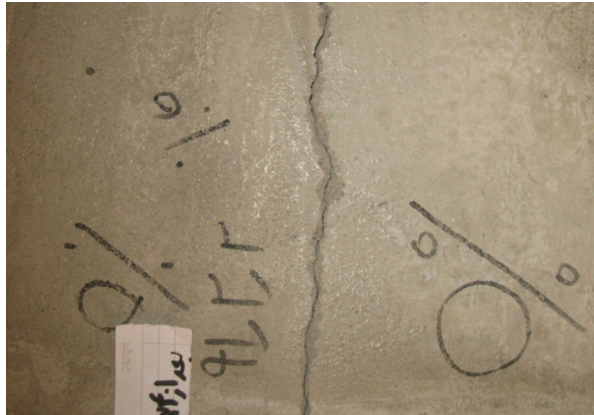

(a)

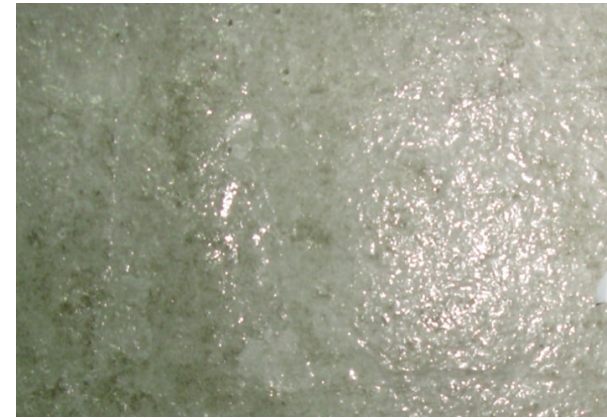

(b)

Figure 2: An example photograph of mortar surface after 24 hours. (a) Mortar without Estabragh fiber showing a crack. (b) Mortar with $0.75 \%$ Estabragh fibers showing no crack.

and compacted on a vibrating table. The specimens were kept covered in their molds for 24 hours. After demoulding of 24hour mortar specimens, they were placed in $20 \pm 2^{\circ} \mathrm{C}$ water for 7 and then 28 days. Two hours before carrying out the tests on 7- and 28-day old specimens, they were brought out from water and placed in the laboratory environment. All tests were performed according to relevant ASTM standards. The cube specimens were tested at 7 and 28 days from casting for their bending strength using a universal testing machine of capacity of 20 tones. In bending tests, each specimen breaks into two pieces. These half-broken pieces were used as the specimens for compressive strength. The compressive strength was measured using the same testing machine. The results for each specimen are based on an average value of three replicate specimens.

\section{Results and Discussions}

The results show that the strength of Estabragh fibers decreases after 28 days of exposure to $\mathrm{NaOH}$ from $3.65 \mathrm{CN}$ to $2.17 \mathrm{CN}$ (Table 1). This means that the Estabragh fibers have poor alkali resistance. Therefore, these fibers are good only for improving the short-term phenomenon in mortar mixture such as surface cracks of cement composites.
The volume of cement composites is usually changed either autogenous or induced. The loss of moisture contained in hardened cement composites causes one of the most detrimental properties of them, which affects the long-term strength and durability. This change is important from the point of view that it causes unsightly cracks in cement composites. Generation of crack in the cement composites is the major factor in destruction. The effect of added fibers on shrinkage behavior of mortar shows that the shrinkage value of mortar specimens decreases by utilizing the Estabragh fibers. Figure 2 shows an example photograph of mortar surface with and without Estabragh fibers. All cracks on the surface of a specimen are traced and then photographed. Figures 3 and 4 show the mean cracks width and mean number of cracks on the surface of 24-hour-old specimens, respectively. As these figures show, the increase in fiber proportioning seemed to result in a reduction in the mean cracks width and number of cracks in unit area when compared with the results of plain mortar. These results could be due to the efficacy of fiber reinforcement in the arrest of cracking, which results from drying shrinkage $[27,28]$. When a crack is formed in fiber-reinforced cement composite, fibers that bridge the crack prevent it from opening more. With the action of shrinkage, fibers transmit forces through the crack. 


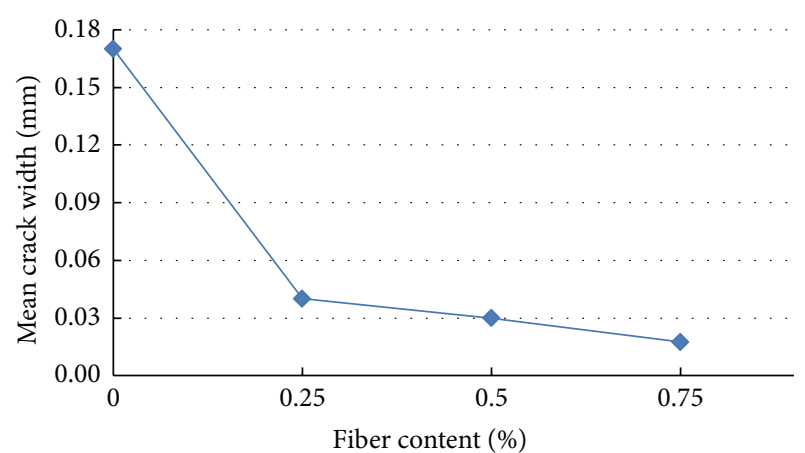

FIGURE 3: Mean crack width on the surface of mortar after 24 hours.

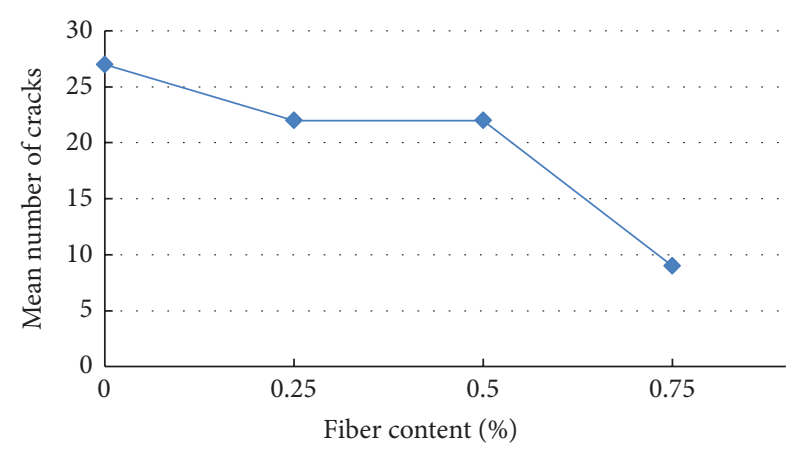

FIGURE 4: Mean number of cracks on the surface of mortar after 24 hours.

If loads transmitted by fibers are very small, as for composites containing either very low volumes, then the second crack will not form because the tensile stress transmitted across the crack is smaller than the tensile strength of the matrix.

As Figure 3 shows, the width of the cracks extremely decreases with adding a small amount of Estabragh fibers $(0.25 \%)$ into the cement composite of mortar. The width of the cracks even shows more decreases as the percentage of Estabragh fibers increases from $0.25 \%$ to $0.75 \%$.

Although, as Figure 4 shows, the number of cracks for $0.25 \%$ and $0.5 \%$ of Estabragh fibers content of mortar specimens show a smooth decrease comparing with that of the plain mortar, but the smaller width of the cracks in these specimens explains the role of fibers in controlling the shrinkage of the cement composite of mortar.

Consequently, adding the Estabragh fibers into the cement composite of mortar causes lower shrinkage of the composite that can be illustrated by lower number of cracks in unit area of the mortar surface and their lower mean width.

Figure 5 shows the mean bending strength of mortar. As it is evident from this Figure, an enhancement in bending strength compared to control sample occurs for the $0.25 \%$ Estabragh fiber mortar at 7 days of curing, while the bending strength of mortar decreases as the fiber proportion increases. The bending strength of $0.25 \%$ Estabragh fiber-reinforced mortar shows no significant difference in comparison with the plain mortar at 28 days, while it decreases as the fiber proportion increases. The same results could be also observed for compressive strength (Figure 6). The lower bending

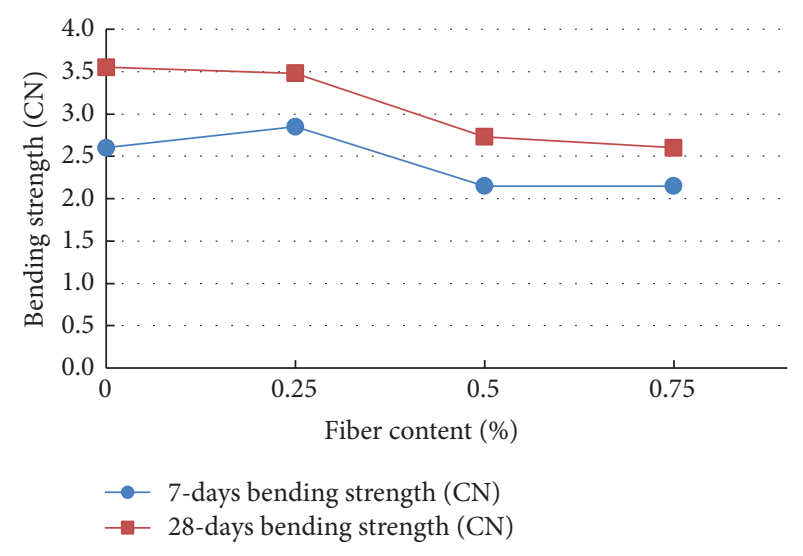

FIGURE 5: Mean bending strength of mortar.

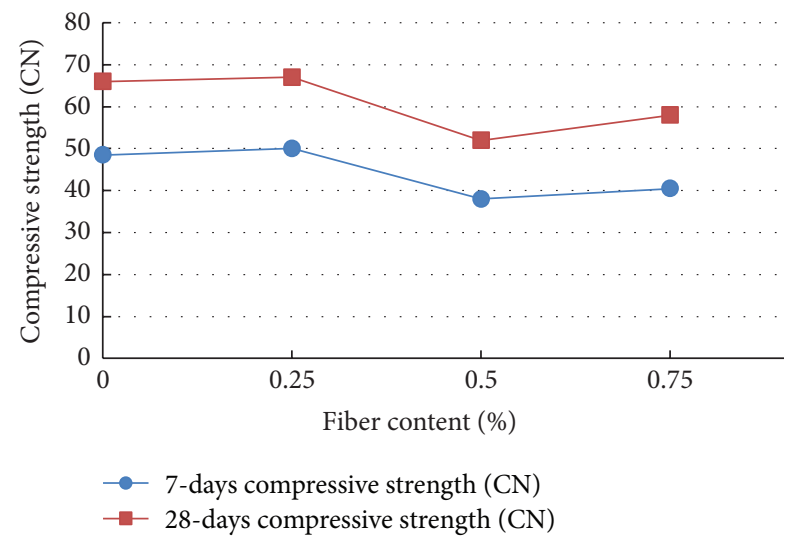

Figure 6: Mean compressive strength of mortar.

strength and compressive strength of higher Estabragh fiber content mortar are due to irregular dispersion of fibers in the matrix of mortar and formation of fiber ball in the composite.

The formation of fiber ball in the composite causes either decreases individual fiber-mortar interfaces or increases fiber-fiber contacts. In the zones of mortar with fiber ball, the bending and compressive forces concentration happens and consequently the mortar specimen breaks at these zones with smaller forces than required for the breaking force of a plane mortar.

Therefore, it is concluded that the Estabragh fibers do not change the bending strength and compressive strength of the cement composite of mortar at low rate of Estabragh fibers $(0.25 \%)$.

\section{Conclusion}

The primary objective of this study was to evaluate the performance of Estabragh fibers at different volume fractions to obtain good physical and mechanical behaviors of cement composites. Estabragh fiber significantly decreases the shrinkage of the mortar. The shrinkage of the cement composite is illustrated by the number of the cracks and their width on the surface of specimen. The results showed that the number of cracks and their width decrease by 
adding the Estabragh fibers into the cement composite of mortar. Therefore, the reinforced mortar specimens display improvement in their shrinkage properties as a result of fibers performance in cement matrix at all fiber proportions of $0.25 \%, 0.5 \%$, and $0.75 \%$.

However, considering the mechanical properties of specimens such as bending strength and compressive strength, among all fiber proportions, only the specimens with $0.25 \%$ of Estabragh fiber performed better in all respects compared to the physical and mechanical properties of reinforced cement composite of mortar. Consequently, by adding $0.25 \%$ of Estabragh fibers to the cement mortar, a remarkable inhibition in crack generation on cement composite of mortar is achieved.

\section{References}

[1] A. A. Gharehaghaji and S. H. Davoodi, "Mechanical damage to estabragh fibers in the production of thermobonded layers," Journal of Applied Polymer Science, vol. 109, no. 5, pp. 30623069, 2008.

[2] A. Bentur and S. Mindess, Fiber Reinforced Cementitious Composites, Taylor and Francis, Landon, UK, 2th edition, 2007.

[3] E. Holt and M. Leivo, "Cracking risks associated with early age shrinkage," Cement and Concrete Composites, vol. 26, no. 5, pp. 521-530, 2004.

[4] X. U. Fang, Z. Mingkai, L. Beixing, and S. Weiguo, "Influence of mineral admixtures on the performance of polymer modified porous concrete," Advanced Materials Research, vol. 87, pp. 9297, 2010.

[5] N. A. Libre, M. Shekarchi, M. Mahoutian, and P. Soroushian, "Mechanical properties of hybrid fiber reinforced lightweight aggregate concrete made with natural pumice," Construction and Building Materials, vol. 25, no. 5, pp. 2458-2464, 2011.

[6] M. Perez-Pena and B. Mobasher, "Mechanical properties of fiber reinforced lightweight concrete composites," Cement and Concrete Research, vol. 24, no. 6, pp. 1121-1132, 1994.

[7] A. G. B. Ritchie and O. Kayali, "The effects of fibre reinforcement on lightweight aggregate concrete," in Proceedings of the RILEM Symposium on Fibre Reinforced Cement and Concrete, A. Neville, Ed., pp. 247-256, The Construction Press, 1975.

[8] O. Kayali, M. N. Haque, and B. Zhu, "Some characteristics of high strength fiber reinforced lightweight aggregate concrete," Cement and Concrete Composites, vol. 25, no. 2, pp. 207-213, 2003.

[9] R. Bagherzadeh, A.-H. Sadeghi, and M. Latifi, "Utilizing polypropylene fibers to improve physical and mechanical properties of concrete," Textile Research Journal, vol. 82, no. 1, pp. 88-96, 2012.

[10] H. R. Pakravan, M. Jamshidi, and M. Latifi, "Performance of fibers embedded in a cementitious matrix," Journal of Applied Polymer Science, vol. 116, no. 3, pp. 1247-1253, 2010.

[11] R. Bagherzadeh, H. R. Pakravan, A. Sadeghi, M. Latifi, and A. A. Merati, "An investigation on adding polypropylene fibers to reinforce lightweight cement composites (LWC)," Journal of Engineered Fibers and Fabrics, vol. 7, no. 4, pp. 13-21, 2012.

[12] D. J. Kim, E. N. Antoine, and E. T. Sherif, "Comparative flexural behavior of four fiber reinforced cementitious composites," Cement and Concrete Composites, vol. 30, no. 10, pp. 917-928, 2008.
[13] S. P. Shah, M. Sarigaphuti, and M. E. Karaguler, "Comparison of shrinkage cracking performance of different types of fibres and wiremesh," in Fiber Reinforced Concrete Developments and Innovations, vol. 142, pp. 1-18, ACI, 1994.

[14] N. Banthia, M. Azzabi, and M. Pigeon, "Restrained shrinkage tests on fiber reinforced cementitious composites," in Testing of Fiber Reinforced Concrete, vol. 155, pp. 137-151, ACI, 1995.

[15] P. S. Song, S. Hwang, and B. C. Sheu, "Strength properties of nylon- and polypropylene-fiber-reinforced concretes," Cement and Concrete Research, vol. 35, no. 8, pp. 1546-1550, 2005.

[16] A. M. Alhozaimy, P. Soroushian, and F. Mirza, "Mechanical properties of polypropylene fiber reinforced concrete and the effects of pozzolanic materials," Cement and Concrete Composites, vol. 18, no. 2, pp. 85-92, 1996.

[17] H. Tanyildizi, "Statistical analysis for mechanical properties of polypropylene fiber reinforced lightweight concrete containing silica fume exposed to high temperature," Materials and Design, vol. 30, no. 8, pp. 3252-3258, 2009.

[18] P. Soroushian, M. Nagi, and J.-W. Hsu, "Optimization of the use of lightweight aggregates in carbon fiber reinforced cement," ACI Materials Journal, vol. 89, no. 3, pp. 267-276, 1992.

[19] R. V. Balendran, F. P. Zhou, A. Nadeem, and A. Y. T. Leung, "Influence of steel fibres on strength and ductility of normal and lightweight high strength concrete," Building and Environment, vol. 37, no. 12, pp. 1361-1367, 2002.

[20] W. R. Malisch, "Polypropylene fibers in concrete, what do the test tell us?" Concrete Construction, vol. 31, no. 4, pp. 363-368, 1986.

[21] P. P. Kraai, "A Proposed test to determine the cracking potential due to drying shrinkage of concrete," Concrete Construction, vol. 30, no. 9, pp. 775-778, 1985.

[22] S. Mindess and G. Vondran, "Properties of concrete reinforced with fibrillated polypropylene fibres under impact loading," Cement and Concrete Research, vol. 18, no. 1, pp. 109-115, 1988.

[23] B. P. Hughes and N. I. Fattuhi, "Improving the toughness of high strength cement paste with fibre reinforcement," Composites, vol. 7, no. 3, pp. 185-188, 1976.

[24] W. Chen and H. J. H. Brouwers, "Alkali binding in hydrated Portland cement paste," Cement and Concrete Research, vol. 40, no. 5, pp. 716-722, 2010.

[25] S. Martinez-Ramirez and A. Palomo, "Microstructure studies on Portland cement pastes obtained in highly alkaline environments," Cement and Concrete Research, vol. 31, no. 11, pp. 15811585, 2001.

[26] N. Reddy and Y. Yang, "Non-traditional lightweight polypropylene composites reinforced withmilkweed floss," Polymer International, vol. 59, no. 7, pp. 884-890, 2010.

[27] P. Balaguru and K. Slattum, "Test methods for durability of polymeric fibers in concrete and UV light exposure," The American Concrete Institute, vol. 155, no. 8, pp. 115-136, 1995.

[28] N. S. Berke and M. P. Dallaire, "The effect of low addition rates of polypropylene fibers on plastic shrinkage cracking and mechanical properties of concrete," in Fiber Reinforced Concrete Developments and Innovations, vol. 142, pp. 19-42, ACI, 1994. 

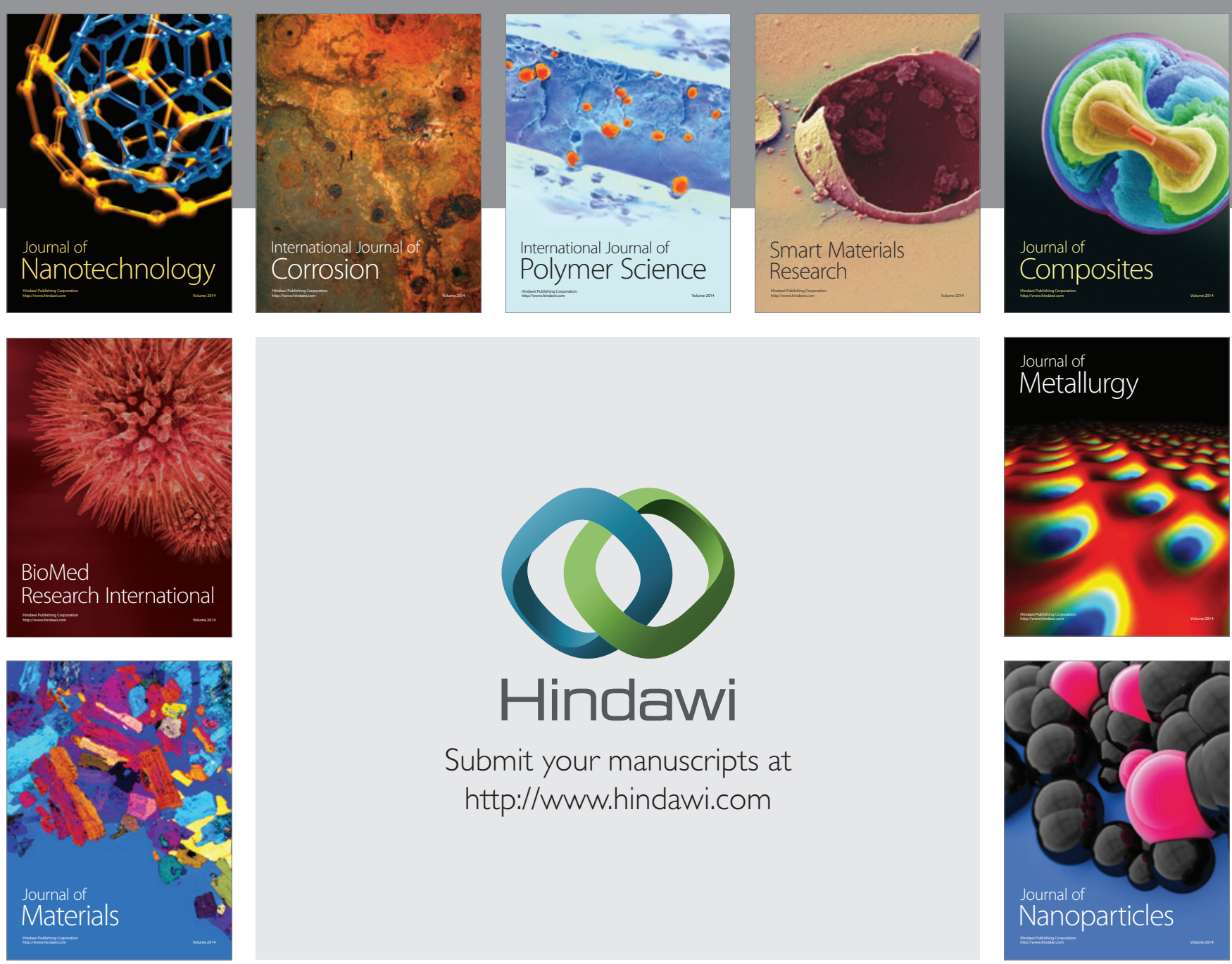

Submit your manuscripts at http://www.hindawi.com
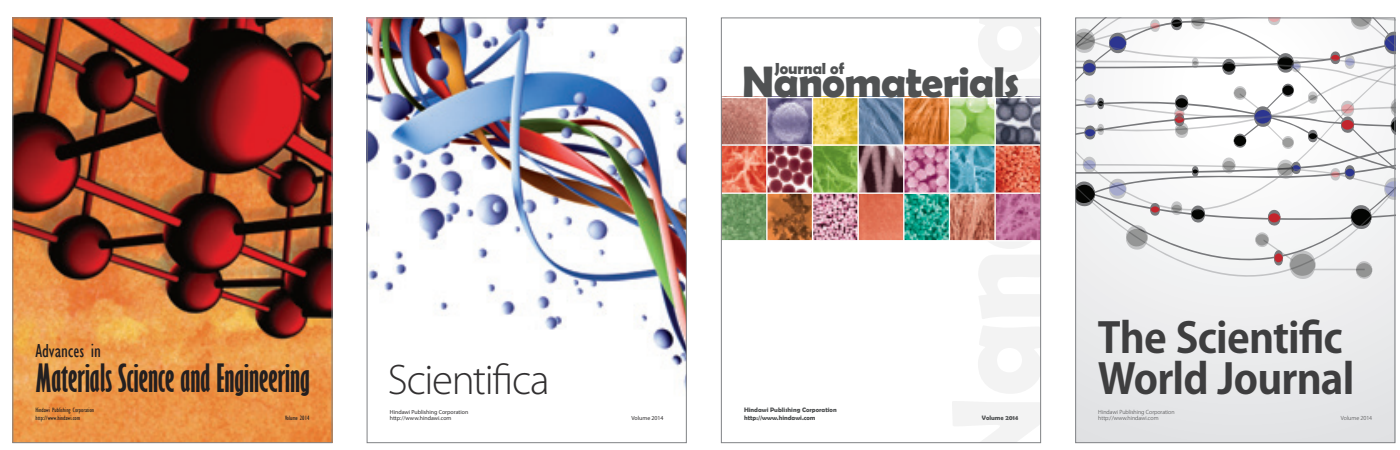

\section{The Scientific World Journal}
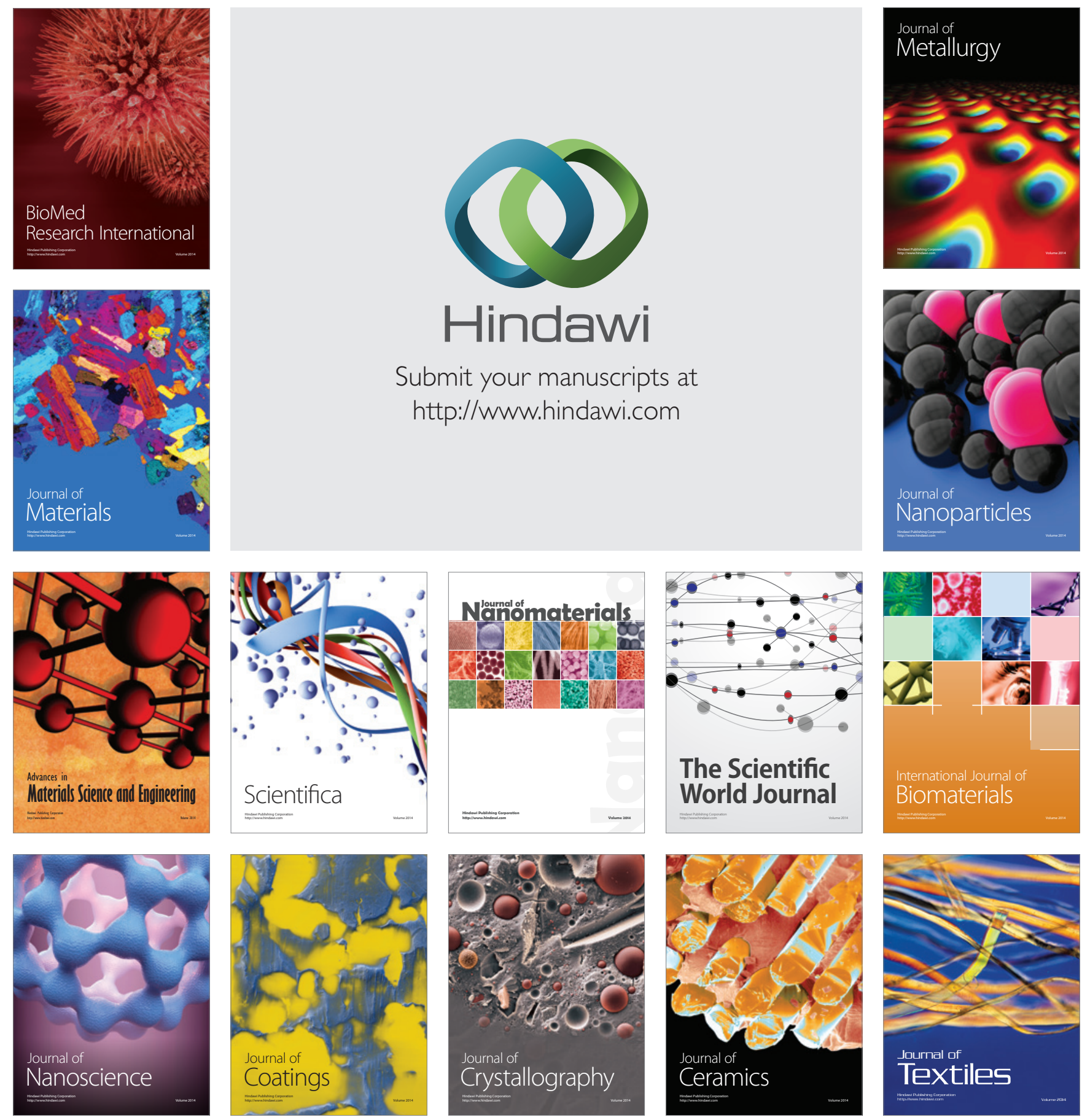